\title{
ANALISIS STRATEGI PEMASARAN PELAYANAN SKIN MEDICAL CENTER DI RUMAH SAKIT PKU MUHAMMADIYAH YOGYAKARTA
}

\author{
Endri Hariyanti, Rosyidah \\ Fakultas Kesehatan Masyarakat, Universitas Ahmad dahlan, Yogyakarta
}

\begin{abstract}
Background: Service center medical skin is a new service PKU Muhammadiyah Hospital in Yogyakarta, the necessary research to find out the marketing strategy plan that will be used PKU Muhammadiyah Hospital in Yogyakarta. The marketing strategies of medical skin care center that will be researched to see of the marketing mix, consisting of product, price, place, promotion, people, processes and Physical evidence, from the marketing mix in the analysis using the SWOT analysis to determine the right strategy.

Method: The study was descriptive qualitative research. The subjects in this study were the Director of Medical Services, Marketing Manager, one Marketing staff, dermatologist and six patients. The instrument used a form of interview guidelines and the type of recorder. Data analysis Used SWOT analysis.

Results: (1) Aspects of the product; Products used in cooperation with Ristra because Ristra is a product that has been certified legal, so safe to use MUI emergency. (2) Aspects of the price, price is still relatively cheap because they still get the discount. (3) Aspects of the place; PKU Muhammadiyah Hospital in Yogyakarta strategically located alongside the highway easily accessible by any transportation making it easier for patients to come to the skin medical center. (4) Promotion: Promotion is not maximized, not broad market area just around the DIY. (5) People; trained human resources, good, loyal and work according to the procedure, Consumers who feel happy and satisfied with the services provided at the medical center skin. (6) Physical evidence; facilities and infrastructure such as physical buildings, medical equipment provided by hospital and has been standard. (7) Process: The process of medical skin care center for treatment tailored to the criteria that will be used in patient care, marketing process of the skin as support medical center for promotional material.

Conclusion: The PKU Muhammadiyah Hospital in Yogyakarta in cooperation with the product Ristra because. legal and safe to use, its strategic location but the parking lot should be disciplined, the promotion should be more leverage and targets a broader region, based on SWOT analysis the most appropriate strategy used PKU Muhammadiyah Hospital in Yogyakarta is an aggressive strategy because it can be made in reference to using a strategy oriented to growth stage.
\end{abstract}

Keywords: Skin Medical Center Services, Marketing Mix, SWOT analysis, Strategic Marketing

\section{PENDAHULUAN}

Strategi pemasaran adalah pendekatan pokok yang akan digunakan oleh unit bisnis dalam mencapai yang telah ditetapkan lebih dulu, didalamya tercantum keputusan-keputusan pokok mengenai target pasar, penempatan produk, di pasar bauran pemasaran dan tingkat biaya pemasaran yang diperlukan. ${ }^{1}$

Skin Medical Center adalah layanan baru di bidang kesehatan kulit yang di tangani oleh Dokter-dokter spesialis kulit Rumah Sakit PKU Muhammadiyah Yogyakarta. Layanan ini menggunakan produk kosmetik yang aman dan didukung alatalat elektromedik yang telah teruji. Ristra adalah merek produk yang telah mendapat sertifikat halah dari MUI sehingga aman untuk digunakan. Alasan tersebut yang 
membuat Pihak Rumah Sakit PKU Muhammadiyah Yogyakarta memilih bekerjasama dengan Ristra di bidang pelayanan skin medical center.

Pemasaran pelayanan skin medical center terdapat kendala-kendala yaitu dalam mengenalkan kepada masyarakat yang sudah menggunakan produk kecantikan lain, sehingga SDM yang dimiliki oleh Rumah Sakit PKU Muhammadiyah dituntut untuk dapat berkomunikasi dengan baik kepada masyarakat agar mereka tertarik dengan produk yang ditawarkan, program pemasaran belum jelas, sehingga perlu adanya strategi pemasaran.

Rumah sakit harus mempunyai suatu perencanaan strategi pemasaran yang baik, bermutu dan berkualitas, dimana strategi pemasaran diharapkan dapat meningkatkan minat kunjungan pasien yang datang untuk berobat atau menggunakan jasa pelayanan (skin medical center) pada Rumah Sakit PKU Muhammadiyah Yogyakarta. Peneliti melakukan penelitian dengan tujuan menganalisis Strategi Pemasaran Pelayanan Skin Medical Center di Rumah Sakit PKU Muhammadiyah Yogyakarta.

\section{METODE PENELITIAN}

Jenis penelitian yang digunakan adalah penelitian deskriptif dengan pendekatan kualitatif. $^{2}$ Tempat Penelitian ini akan dilaksanakan di Rumah Sakit PKU Muhammadiyah Yogyakarta dan subjek penelitian yaitu Direksi Pelayanan Medis, manajer pemasaran Rumah Sakit PKU Muhammadiyah Yogyakarta, 1 orang staf pemasaran Rumah Sakit PKU Muhammadiyah Yogyakarta, 1 Dokter spesialis Kulit dan pasien yang menggunakan pelayanan hemodialisa. Alat yang digunakan adalah berupa panduan wawancara dan tipe recorder. Variabel yang diuji adalah variabel tunggal, yaitu Analisis Strategi Pemasaran Pelayanan skin medical center di Rumah Sakit PKU Muhammadiyah Yogyakarta. Teknik yang digunakan untuk menguji kredibilitas data adalah triangulasi dengan sumber yaitu, membandingkan atau mengecek balik derajat kepercayaan suatu informasi yang diperoleh melalui waktu dan alat yang berbeda dalam penelitian kualitatif.

\section{HASIL PENELITIAN DAN PEMBAHASAN}

\section{a. Bauran Pemasaran}

1) Aspek Produk: Produk yang digunakan bekerjasama dengan produk Ristra karena Ristra Sudah mempunyai sertifikat halah dari MUI sehingga aman dikonsumsi .

2) Aspek Harga:Penetapan tarif di hitung berdasarkan komponen seperti jasa dokter, jasa RS, bahan habis pakai,Investasi dan pembayaran royalti, namun dalam penentuan tarif tidak lepas dari unsur sosial jadi tarif yang di berikan tidak memberatkan konsumen dengan memberikan diskon harga.

3) Aspek Tempat; Tempat pelayanan skin medical center sangat strategis berada di pusat kota sehingga mudah di jangkau oleh transportasi apapun.

4) Aspek Promosi: Promosi yang dilakukan yaitu bekerjasama dengan Adi-TV, penyebaran brosur, leafleat, pemasangan spanduk, dan melalui surat kabar.

5) Aspek People; Karyawan yang ada pada pelayanan skin medical center sudah profesional dan mempunyai skill di bidang skin care sehingga dengan pelayanan 
yang diberikan pasien merasa nayaman dan senang sehingga hal ini bisa juga dijadikan promosi yang baik.

6) Aspek Phisycal Evidence; sarana dan prasarana pada pelayanan skin medical center sudah sesuai standar.

7) Aspek Proses: proses pelayanan yaitu pasien datang, mengisi identitas, kemudian analisis wajah, setelah itu konsultasi dengan dokter, dari hasil konsultasi ditentuka tindakan apa yang sebaiknya di gunakan pasien, setelah selesai lalu pasien bayar administrasi.

b. Analisis Kekuatan, kelemahan, peluang dan ancaman pelayanan skin medical center Di rumah Sakit PKU Muhammadiyah Yogyakarta.

1) Kekuatan ( Strength)

a) Produk sudah teruji keamananya dan memiliki sertifikat halal dari MUI

b) Dokter yang menangani dokter spesialis kulit

c) Harganya masih di tengah-tengah artinya lebih murah dibanding Rumah Sakit X.

d) Lokasi Stategis

e) Kerjasama yang bagus dengan Pemasok

f) SDM terlatih dan mempunyai skil di bidang skin care

2) Kelemahan
a) Area parkir sempit
b) Gudang penyimpanan produk terbatas
c) Harga Diskon tidak untuk semua produk
d) SDM terbatas
e) Dana promosi sedikit
f) Promosi belum maksimal
g) Program pemasaran belum terinci secara jelas

3) Peluang
a) Pengembangan lokasi skin medical center
b) Kerjasama dengan lembaga lain sebagai pendukung pemasaran
c) SDM yang berkualitas
d) Kerjasama yang baik dengan pemasok(PT Ristra)

4) Ancaman
a) Banyak berdiri skin care
b) Pemutusan hubugan sepihak dengan Ristra
c) Harga kurang diskon atau beberapa produk masih mahal
d) Inovasi promosi ditiru orang
e) Jika SDM tidak bisa memberikan pelayanan dengan baik.

\section{c. Pembahasan}

1) Aspek Produk: Dalam pengembangan produk Rumah Sakit PKU bekerjasama dengan PT Ristra, Ristra merupakan produk kosmetik yang dianggap aman dan sesuai dengan visi Rumah Sakit PKU Muhammadiyah Yogyakarta karena Ristra sudah mendapatkan sertifikat halal dari MUI hal ini tentu saja mendapatkan respon positif dari masyarakat, sehingga membuat masyarakat tertarik untuk 
menggunakan pelayanan skin medical center di Rumah Sakit PKU Muhammadiyah Yogyakarta selain itu penanganannya dibawah pengawasan dokter spesialis kulit.

2) Aspek Harga: Penetapan tarif pelayanan skin medical center disesuaikan atas kesepakatan antara Rumah Sakit PKU Muhammadiyah Yogyakarta dengan PT ristra, adapun komponen dalam penetapan tarif meliputi jasa dokter, jasa rumah sakit, bahan habis pakai, investasi alat dan pembayaran royalti kepada pihak Ristra. Pemberian diskon.

3) Aspek Tempat; Lokasi Rumah Sakit PKU Muhammadiyah Yogyakarta sangat strategis, terletak di pusat kota, tempat Pelayanan skin medical center berada paling depan dari Rumah sakit PKU Muhammmudah di tepi jalan besar mudah dijangkau atau diakses alat transportasi apapun sehingga hal ini yang memudahkan pasien untuk datang ke Rumah Sakit PKU Muhammadiyah Yogyakarta khususnya pada pelayanan skin medical center. Namun wilayah pemasaran pelayanan skin medical center kurang luas hanya di sekitar pusat kota jogja sehingga masyarakat luar Kota Yogyakarta belum mengetahui adanya pelayanan skin medical center di Rumah Sakit PKU Muhammadiyah Yogyakarta.

4) Aspek Promosi: Promosi Rumah Sakit PKU Muhammadiayah Yogyakarta khususya dalam memasarkan pelayanan skin medical center bekerja sama dengan ADI-TV dengan cara menyampaikan informasi mengenai pelayanan skin medical center di Rumah Sakit PKU Muhammadiyah Yogyakarta, menggunakan media brosur-brosur, surat kabar, spanduk dan leafleat, dengan media tersebut tentu saja bisa menarik perhatian masyarakat sehingga masyarakat mengetahui informasi mengenai pelayanan skin medical center di Rumah Sakit PKU Muhammadiya Yogyakarta.

5) Aspek People;.

a) Karyawan atau tenaga pelayanan skin medical center sudah mendapatkan pelatihan di bidang masing-masing hal ini sangat memuaskan pasien karena dengan keterampilan dan keahlian yang dimiliki meraka bisa memberikan pelayananan yang baik sehingga pasien merasa nyaman dan senang.

b) Konsumen yang ada pada pelayanan skin medical center mempunyai penilaian yang berbeda-beda ada yang merasa puas ada juga yang tidak puas, pasien yang merasa tidak puas baik dari segi pelayanan atau harga yang diberikan mereka akan komplain, tetapi jika pasien merasa puas mereka akan menjadi sarana promosi yang baik, karena dapat mempengaruhi persepsi pelanggan lainnya.

6) Aspek Phisycal Evidence; Konsumen yang ada pada pelayanan skin medical center mempunyai penilaian yang berbeda-beda ada yang merasa puas ada juga yang tidak puas, pasien yang merasa tidak puas baik dari segi pelayanan atau harga yang diberikan mereka akan komplain, tetapi jika pasien merasa puas mereka akan menjadi sarana promosi yang baik, karena dapat mempengaruhi persepsi pelanggan lainnya. 
7) Aspek Proses; Proses dalam hal ini terkait dengan proses pelayanan jasa yang diberikan skin medical center di Rumah Sakit PKU Muhammadiyah Yogyakarta kepada konsumen sehingga konsumen merasa puas dan mempunyai penilaian baik. Prosedur pasien baru pada pelayanan skin medical center yaitu: pasien datang, mendafatar mengisi identitas, kemudian analisis wajah, setelah itu konsultasi dengan dokter, dari hasil konsultasi dapat ditentukan tindakan atau perawatan yang akan digunakan pasien, setelah pasien selesai mendapatkan perawatan, lalu membayar di bagian kasir. Matrik Analisis SWOT Pelayanan Skin Medical Center Di Rumah Sakit

PKU Muhammadiyah Yogyakarta

\begin{tabular}{|c|c|c|}
\hline $\begin{array}{l}\text { EFAS } \\
\text { (Faktor strategi } \\
\text { eksternal) }\end{array}$ & $\begin{array}{l}\text { STRENGHT (S) } \\
\text { 1. Produk sudah teruji kea- } \\
\text { mananya dan memiliki sertifikat } \\
\text { halal dari MUI } \\
\text { 2. Dokter yang menangani dokter } \\
\text { spesialis kulit } \\
\text { 3. Harganya masih di tengah- } \\
\text { tengah artinya lebih murah di- } \\
\text { banding rumah sakit X. } \\
\text { 4. Lokasi Strategis } \\
\text { 5. Kerjasama yang bagus dengan } \\
\text { Pemasok } \\
\text { 6 SDM terlatih dan mempunyai skil } \\
\text { di bidang skin care }\end{array}$ & $\begin{array}{l}\text { WEAKNESESS(W) } \\
\text { 1. Area parkir sempit } \\
\text { 2. Gudang penyimpanan produk } \\
\text { terbatas } \\
\text { 3. harga diskon tidak untuk se- } \\
\text { mua produk } \\
\text { 4. SDM terbatas } \\
\text { 5. Dana promosi sedikit } \\
\text { 6. Promosi belum maksimal } \\
\text { 7. Program pemasaran belum } \\
\text { terinci secara jelas }\end{array}$ \\
\hline $\begin{array}{l}\text { OPURTUNITIES (O) } \\
\text { 1. Pengembangan lokasi skin } \\
\text { medical center } \\
\text { 2. Kerjasama dengan lembaga } \\
\text { lain sebagai pendukung pema- } \\
\text { saran } \\
\text { 3. SDM yang berkualitas } \\
\text { 4. Kerjasama yang baik dengan } \\
\text { pemasok(PT Ristra) }\end{array}$ & $\begin{array}{l}\text { Strategi SO } \\
\text { 1. Kualitas produk yang bagus } \\
\text { maka rumah sakit dapat } \\
\text { mengembangkan jenis produk } \\
\text { dan menaikkan harga } \\
\text { 2. SDM yang terlatih dan yang } \\
\text { berkualitas meningkatkan } \\
\text { kepuasan pasien } \\
\text { 3. Kerja sama yang bagus dengan } \\
\text { pemasok(Ristra) sangat bagus } \\
\text { untuk kelangsungan siklus hidup } \\
\text { produksi } \\
\text { 4. Memperluas lokasi skin medical } \\
\text { center }\end{array}$ & $\begin{array}{l}\text { Strategi WO } \\
\text { 1. Memperluas lokasi } \\
\text { 2. Meningkatkan anggaran dana } \\
\text { untuk promosi agar promosi } \\
\text { bisa maksimal } \\
\text { 3. Menambah Sumberdaya } \\
\text { manusia yang berkualitas } \\
\text { 4. Semakin mempererat ker- } \\
\text { jasama dengan PT ristra }\end{array}$ \\
\hline $\begin{array}{l}\text { THREATS }(T) \\
\text { 1. Banyak berdiri skin care } \\
\text { 2. Pemutusan hubugan sepihak } \\
\text { dengan Ristra } \\
\text { 3. Harga kurang diskon atau } \\
\text { beberapa produk } \\
\text { masih mahal } \\
\text { 4. Inovasi promosi ditiru orang } \\
5 \text { Jika SDM tidak bisa memberi- } \\
\text { kan pelayanan dengan baik. }\end{array}$ & $\begin{array}{l}\text { Strategi ST } \\
\text { Membina Hubungan kerjasama } \\
\text { dengan pemasok (Ristra) dengan } \\
\text { baik penetapan harga yang jelas } \\
\text { dan pembagian royalti sesuai } \\
\text { kesepakatan bersama, mening- } \\
\text { katkan kualitas produk dan pelaya- } \\
\text { nan agar pasien puas sehingga } \\
\text { bisa merebut pasar }\end{array}$ & $\begin{array}{l}\text { Strategi WT } \\
\text { Membuat program pemasaran } \\
\text { yang jelas, memaksimalkan pro- } \\
\text { mosi, pemberian diskon yang } \\
\text { merata }\end{array}$ \\
\hline
\end{tabular}

Alternatif Strategi Pemasaran Pelayanan Skin Medical Center Di Rumah Sakit PKU Muhammadiyah Yogyakarta. Setelah di analisis kekuatan, kelemahan, peluang dan ancaman dengan menggunakan analisis swot, langkah selanjutnya membuat Strategi pemasaran, sebelumnya strategi pemasaran pelayanan skin medical center belum terprogram secara jelas melihat kondisi Rumah Sakit PKU Muhammadiyah Yogyakarta khususnya dalam memasarkan pelayanan skin medical center saat ini strategi yang tepat adalah strategi SO (Strategi Agresif) strategi ini dipilih karena berdasarkan analisis yang ada lebih banyak kekuatan dan peluang 
dibandingkan dengan ancaman dan kelemahan. Situasai pada posisi strategi agresif adalah situasi yang paling bagus bagi rumah sakit dalam menghadapi berbagai kemungkinan untuk memperoleh peluang dan mempunyai berbagai kekuatan untuk memperoleh peluang tersebut. ${ }^{3}$

\section{SIMPULAN DAN SARAN}

\section{a. Simpulan}

1) Bauran pemasaran pelayanan skin medical center di Rumah Sakit PKU Muhammadiyah Yogyakarta mencakup tujuh aspek sebagai berikut :

a) Skin medical center merupakan pelayanan baru di Rumah Sakit PKU Muhammadiyah Yogyakarta Produk yang digunakan bekerjasama dengan Ristra karena produk Ristra sudah mendapat sertifikat halal dari MUI sehingga aman untuk digunakan.

b) Lokasi Rumah Sakit PKU Muhammadiyah Yogyakarta sangat strategis berada di tengah-tengah kota dan mudah dijangkau dengan menggunakan alat transportasi apa saja.

c) Tarif pelayanan skin medical center masih pada posisi tengah-tengah karena baru tahap perkenalan produk sehingga masih memberikan diskon.

d) Media Promosi yang digunakan untuk memasarkan pelayanan skin medical center berupa penyebaran brosur-brosur, surat kabar, memasang spanduk, bekerjasama juga dengan ADI-TV.

e) People terkait dengan SDM dan konsumen, SDM yang ada pada pelayanan skin medical center sudah mendapatkan pelatihan dibidang skin care dokter yang menangani pasien merupakan dokter spesialis kulit, konsumen berasal dari semua kalangan baik remaja, ibu-ibu ataupun kaum laki-laki tanggapan mereka cukup bagus dengan pelayanan skin medical center di Rumah Sakit PKU Muhammadiyah Yogyakarta.

f) Sarana dan prasarana skin medical center ini baik bangunan fisik tempat, lokasi, peralatan semua di fasilitasi oleh Rumah Sakit PKU Muhammadiyah Yogyakarta.

g) Proses penyediaan jasa pelayanan skin medical center khususnya untuk beberapa treatment disesuaikan dengan kriteria jenis perawatan yang diinginkan oleh pasien, sehingga perawatan yang diberikan kepada pasien itu sesuai dengan permasalahan kulit yang dialami hal ini, juga mempengaruhi tingkat kepuasan pasien teradap pelayanan yang diberikan.

2) Berdasarkan Matrik Analisis SWOT maka strategi yang paling tepat yaitu strategi SO (Strategi Agresif ) karena lebih banyak kekuatan dan peluang dibandingkan dengan ancaman dan kelemahan. Situasai pada posisi strategi agresif adalah situasi yang paling bagus bagi rumah sakit dalam menghadapi berbagai kemungkinan untuk memperoleh peluang dan mempunyai berbagai kekuatan untuk memperoleh peluang tersebut ${ }^{1}$.

\section{b. Saran}

1) Sebaiknya distribusi pemasaran pelayanan produk skin medical center di perluas hingga ke luar kota Jogja. 
2) Sebaiknya disediakan kotak saran untuk menampung keluhan pasien dan tiap minggu dilakukan evaluasi guna memperbaikai dan mempertahankan kualitas pelayanan.

3) Melihat ancaman yang ada hendaknya Rumah Sakit PKU Muhammadiyah Yogyakarta lebih memaksimalkan kekuatan yang dimiliki pada pelayanan skin medical center dengan meningkatkan kualitas produk, memberikan pelayanan yang lebih professional, agar pasien lebih puas, sehingga bisa mengantisipasi ancaman.

4) Pihak Rumah Sakit PKU Muhammadiyah Yogyakarta dalam memasarkan pelayanan skin medical center harus jelas mengenai perencanan segmen mana yang akan di bidik, targetnya siapa saja dan positioning produknya bagaimana sehingga hal ini bisa mempermudah untuk menentukan strategi yang akan digunakan.

5) Dengan adanya dokter spesialis kulit maka mempunyai potensi untuk pengembangan produk pelayanan dan lebih mengeksplor potensi yang terdapat pada produk pelayanan skin medical center sehingga dapat meningkatkan kualitas pelayanan.

6) Sebaiknya Pihak Manajemen RS mengevaluasi kembali strategi pemasaran dari aspek promosi yang dugunakan, sehingga pelayanan skin medical center dapat diakses dengan mudah oleh masyarakat luas, misalnya melalui media internet.

\section{DAFTAR PUSTAKA}

1. Kotler, P, Manajemen Pemasaran, Jilid 1, Penerbit Erlangga,1989

2. Moleong, Lexi G.,Metodologi Penelitian Kualitatif., PT Remaja. Rosdakarya. Bandung, 2005

3. Sari W, I, D., Manajemen Pemasaran Usaha Kesehatan, Mitra Cendikia Press, Yogyakarta, 2008 